\title{
Injuries to older users of buses in the UK
}

\author{
Jo Barnes ${ }^{1}$ Andrew Morris ${ }^{1} \cdot$ Ruth Welsh $^{1} \cdot$ Steve Summerskill $^{1}$ • \\ Russ Marshall ${ }^{1} \cdot$ Denise Kendrick $^{2}$ - Pip Logan ${ }^{3}$ Avril Drummond ${ }^{4}$. \\ Simon Conroy ${ }^{5} \cdot$ Brian Fildes $^{6} \cdot$ Julie Bell $^{7}$
}

Accepted: 11 September 2015/Published online: 13 October 2015

(C) The Author(s) 2015. This article is published with open access at Springerlink.com

\begin{abstract}
The increasing age of the United Kingdom (UK) population coupled with enhanced life expectancy impacts on transport-user demographics and will affect transport planning in the years ahead. Whilst passenger car use is the ultimate means of personal independence, at some point the physiological and psychological impact of age-related conditions will inevitably shift people out of their vehicles and onto public transport systems. Overall, public transport is seen to be vital for social inclusion (Lucas et al. 2008) and it is considered a safe means of mobility. However, it is important that the public and, in particular, the elderly perceive it to be so. Injuries (across a spectrum of severities) do occur during public transport use from time to time. In fact, over 5000 people are injured on UK buses each year alone with over 300 bus-users killed/seriously injured (Department for Transport 2013). This study was designed to examine the nature of injuries and their causes to older bususers with the aim being to establish where design countermeasures may be indicated. The study uses descriptive statistics to analyse linked (accident and injury) data involving a sample of older bus-users. Most incidents in the linked dataset were non-collisions (62\%) resulting in 1381 recorded injuries in those aged $60+$ years, of which $46 \%$ were 'slight' and $54 \%$ 'serious'.
\end{abstract}

$\triangle$ Jo Barnes

j.barnes@lboro.ac.uk

1 Loughborough University Design School, Loughborough, Leics LE11 3TU, UK

2 Division of Primary Care, University of Nottingham, Nottingham, UK

3 Division of Rehabilitation and Ageing, University of Nottingham, Nottingham, UK

4 School of Nursing, University of Nottingham, Nottingham, UK

5 Geriatric Medicine, University Hospitals Leicester, Leicester, UK

6 Monash University Accident Research Centre, Clayton, Australia

7 Health and Safety Laboratory, Buxton, UK 
Keywords Bus $\cdot$ Older passengers $\cdot$ Injury $\cdot 60+$ years $\cdot$ Injury severity $\cdot$ Public transportation

\section{Introduction}

The current estimated population for the UK is 64.1 million people with an expected rise to 73.3 million by 2037 (ONS 2012). It is projected that there will be a rise of $31 \%$ in the number of people of state pension age in the UK from 12.3 million (mid-2012) to 16.1 million (mid-2037), taking into account future rises in the state pension age. This increase in ageing populations will have an impact on various services available to older people in society. Modern societies have a duty of care to help older people live in their homes and communities for as long as they want. The physical environment, and the services upon which older people rely, must be 'agefriendly', so as to remove barriers to their participation in their communities.

In practice, part of this means addressing older people's anxieties regarding incidence of crime, recognising the unique characteristics and needs of people growing older in rural communities, tackling the problems caused by isolation and loneliness and addressing older peoples transport needs. This last point is particularly important as it involves providing a transport system that is safe and secure as well as affordable. In the majority of cases, the public transport of choice is the public bus since this is by far the most common form of public transport provision in terms of numbers and frequency of routes.

In the main, public transport is relatively safe-according to Mabrook (1994), injuries sustained by passengers travelling on public buses are relatively uncommon; public service vehicle passenger casualty rates, per billion passenger kilometre travelled are much lower than for cars, motor-cycles, pedal-cycles and pedestrians. Nevertheless, during the period 2008 to 2012, over 20,000 UK bus and coach users were injured whilst using this form of transport. The problem is not confined to the UK - a study in Israel (Halpern et al. 2005) estimated that as many as 2700 bususers per year might be injured whilst using the bus representing an 'alarmingly high level of morbidity'. However, measuring injury outcomes does not tell the whole story since those not necessarily injured but 'shaken' or 'thrown off balance' whilst using the bus can easily be dissuaded from further bus use. This is principally because of fear of falling or future injury. Ultimately, these events can lead to social exclusivity and ultimately isolation through eventual lack of personal mobility.

Previous studies have looked at characteristics and incidence of accidents in which injuries have occurred to public bus users. An early study is reported by Jovanis et al. (1991) in the USA which looked at 1800 accidents between 1982 and 1984 to identify factors contributing to accidents involving mass transit buses. They observed that on a passenger-mile basis, bus travel has relatively low risk but that as many as $63 \%$ of bus transit accidents involve no collision.

Related studies were conducted in Denmark by Nue Moller et al. (1982) through examining records of 183 injured bus passengers who sustained between them some 212 injuries. 85 of the 183 passengers were injured whilst the bus was in motion and 
58 of these passengers were standing on the bus at the time of the incident with acceleration/deceleration of the bus therefore being a major factor in these accidents. A subsequent Danish study by Albrektsen and Thomsen (1983) looked at 221 bus accidents and incidents in Copenhagen and found that $60 \%$ of their sample were females aged over 60 years with most of the passengers $(n=138)$ sustaining injury whilst the bus was in motion between stops. The vast majority of these (83\%) were found to be standing up at the time of the collision.

Similarly, Kirk et al. (2003) found that in approximately $65 \%$ of cases, there was no actual impact involved and that the injury had occurred to a seated ( $44 \%)$ or standing $(\sim 30 \%)$ passenger whilst the bus was in motion. Their study also found that older females were particularly over-represented and that the likelihood of serious or fatal injury to both males and females increases as age increases. The cause of incidents included slippery and uneven floors, high steps and lack of visual cues.

More recently, Halpern et al. (2005) made similar findings in Israel to those of Kirk et al. (2003) in that $56 \%$ of injuries were sustained by passengers who were either standing or moving in the bus and that the major mechanism of injury was sudden deceleration or acceleration of the bus. Similarly it was found that in $62 \%$ of cases non-collision incidents on buses accounted for the highest incidence of injuries for the older users (Barnes and Morris 2014).

Mabrook (1994) noted that whilst travelling by bus is one of the safest ways to travel, little is written about injuries and injury causation and that some attention could be paid to the design of hand rails or seats which appeared to be the root-cause of many injuries. A report examining the injuries of young and older public transport users in Victoria, Australia identified some 3152 public transport incidents in a 4-year period of which $33 \%$ where bus related. For those $60+$ years $(n=767)$ the main mechanism of injury on buses was recorded as slip/trip/fall (boarding and alighting) for $64 \%$ of cases (Fildes et al. 2012). A recent literature review of older public transport users highlights the limited research undertaken in this area and suggests the incidence of injuries on public transport is underestimated (Kendrick et al. 2015). No study to date has made an in-depth appraisal of injury outcomes to users of buses in order to establish the likely injury mechanisms in order to ascertain which design countermeasures might be feasible in the prevention of such injuries. Therefore, the aim of this study was to provide a descriptive accident analysis matching reports of accidents and injury reports where older users of public bus transportation were injured through everyday use of the public bus. The objective was to highlight the key aspects of bus travel that have an impact on the nature of specific injuries and their severity which can be used to inform future design countermeasures.

\section{Methodology}

Two main United Kingdom national databases have been used in this studynamely the UK national road accident database known as STATS19 and the hospital episodes statistics (HES) database.

The STATS19 database is a national road accident database which is founded on accident records that are completed by police officers in the event of an accident 
occurring on the roads in the United Kingdom. To become a record within the STATS19 database, the accident has to be reported to the police and should involve human injury or death. The STATS19 data collection form collects a wide variety of information about the accident (such as time, date, location, road conditions) together with information about the vehicles and casualties involved and the contributory factors (as interpreted by the police) Department for Transport 2005. The form is completed at either the scene of the accident, or when the accident is reported to the police. In this study, STATS19 data were analysed for the years 2008-2012.

The health episodes statistics (HES) is a data warehouse containing details of all admissions, outpatient appointments and accident and emergency (A\&E) attendances at National Health Service (NHS) hospitals in England. This data is collected during a patient's time at hospital and is a records-based system that covers all NHS trusts in England, including acute hospitals, primary care trusts and mental health trusts. Patient confidentiality is strictly maintained within this database.

To establish injury outcomes in relation to accident characteristics, the STATS19 and HES databases have been linked so that accident records are uniquely matched to injury records.

The record-linking process is described more completely in a separate report (Department for Transport 2012). Linked data were used for the period 1999-2009 during which $41 \%$ of road accident records in STATS19 were successfully linked to a hospital record. The injury severity of the casualties was also categorised according to the most serious injury sustained by the individual based on their maximum abbreviated injury score (MAIS) (AAAM 1998). The severity ranges between 1 and 6 increasing in severity from minor AIS (Abbreviated Injury Scale) 1 to maximal AIS 6 injuries. These severities were calculated from the HES database using a conversion algorithm (ECIP 2006) to convert ICD10 codes (WHO 2010) to a MAIS code.

Table 1 Recorded bus and coach casualties and associated costs

\begin{tabular}{|c|c|c|c|c|}
\hline $\begin{array}{l}\text { Year } \\
\text { All UK casualties } \\
\quad(60+\text { years })\end{array}$ & $\begin{array}{l}\text { All road } \\
\text { casualties (n) }\end{array}$ & $\begin{array}{l}\text { Bus/coach } \\
\text { casualties (n) }\end{array}$ & $\begin{array}{l}\text { Bus/coach casualties } \\
\text { as percentage of } \\
\text { all road casualties }(\%)\end{array}$ & $\begin{array}{l}\text { Bus/coach } \\
\text { casualty } \\
\text { costs }(£)\end{array}$ \\
\hline 2008-all & 230,905 & 6275 & 2.7 & $170,960,344$ \\
\hline $2008(60+$ years $)$ & 24,484 & 2181 & 9 & $76,211,144$ \\
\hline 2009-all & 222,146 & 5735 & 2.6 & $164,918,066$ \\
\hline $2009(60+$ years $)$ & 24,415 & 2113 & 8.7 & $83,517,644$ \\
\hline 2010 -all & 208,64 & 5718 & 2.7 & $159,303,728$ \\
\hline $2010(60+$ years $)$ & 23,522 & 2010 & 8.5 & $67,247,954$ \\
\hline 2011-all & 203,950 & 5688 & 2.8 & $150,555,934$ \\
\hline $2011(60+$ years $)$ & 23,979 & 2048 & 8.5 & $74,388,380$ \\
\hline 2012-all & 195,723 & 4790 & 2.4 & $139,011,302$ \\
\hline $2012(60+$ years $)$ & 23,357 & 1658 & 7.1 & $67,395,066$ \\
\hline Total—all & 1061,372 & 28,206 & 2.7 & $£ 784,749,374$ \\
\hline Total $(60+$ years $)$ & 119,757 & 10,010 & 8.4 & $£ 368,760,188$ \\
\hline
\end{tabular}


This study focuses on public bus and coach passengers aged 60 years and over since this is the age at which senior citizens are offered a free bus-pass and therefore where bus travel is most common within this user-group.

\section{Results}

\subsection{UK STATS19 data analysis}

For the 5 years period 2008 to 2012, 17,728 bus/coach passenger casualties were recorded accounting for $2.7 \%$ of all known road accident casualty types (Table 1). When examining those aged over 60 years, there were 10,010 injured bus/coach passengers nationally over the 5 years period accounting for $8.4 \%$ of all $60+$ casualties. Examination of the average costs for the 5 years period shows that the 60 +years account for some $47 \%$ of the total costs of all bus and coach passenger accident casualties (Department for Transport 2013).

Overall there has been a general trend showing that bus and coach accident casualty costs (which are calculated according to casualty severity) have been declining over the past 5 years (Table 1). However, for the $60+$ years there has been no corresponding decline with a peak in 2009 and a dip in 2010 and 2012.

Most bus/coach passengers (94\%) are recorded as 'slightly injured' casualties with very few fatalities (Table 2). The proportion of 'serious' casualties for the over 60 years was higher at $9.6 \%$ compared to the average $5.9 \%$ for all ages.

The distribution of age in the over 60 years (Table 3) shows that the number of fatalities increased for those in the 70-79 years and 80-89 years age brackets furthermore, there was a corresponding increase in the number of serious injuries. This is further evident in the 60-69 years group where there were similar numbers

Table 2 Severity of all bus and coach passenger and those aged 60+ (2008-2012)

\begin{tabular}{lcccr}
\hline & All bus users & $\%$ & Age 60+ bus users & $\%$ \\
\hline Fatal & 43 & 0.2 & 30 & 0.3 \\
Serious & 1674 & 5.9 & 964 & 9.6 \\
Slight & 26,489 & 94 & 9016 & 90.1 \\
\hline
\end{tabular}

Table 3 Casualty age by casualty severity-bus and coach passengers aged $60+$

\begin{tabular}{|c|c|c|c|c|c|c|c|c|}
\hline & $\begin{array}{l}\text { Age } \\
60-69 \text { years }\end{array}$ & $\%$ & $\begin{array}{l}\text { Age } \\
70-79 \text { years }\end{array}$ & $\%$ & $\begin{array}{l}\text { Age } \\
80-89 \text { years }\end{array}$ & $\%$ & $\begin{array}{l}\text { Age } 90+ \\
\text { years }\end{array}$ & $\%$ \\
\hline Fatal & 5 & 0.1 & 12 & 0.33 & 12 & 0.5 & 1 & 0.3 \\
\hline Serious & 250 & 6.8 & 344 & 9.53 & 323 & 13.5 & 47 & 14.2 \\
\hline Slight & 3425 & 93.1 & 3254 & 90.14 & 2053 & 86 & 284 & 85.5 \\
\hline Total & 3680 & 100 & 3610 & 100 & 2388 & 100 & 332 & 100 \\
\hline
\end{tabular}




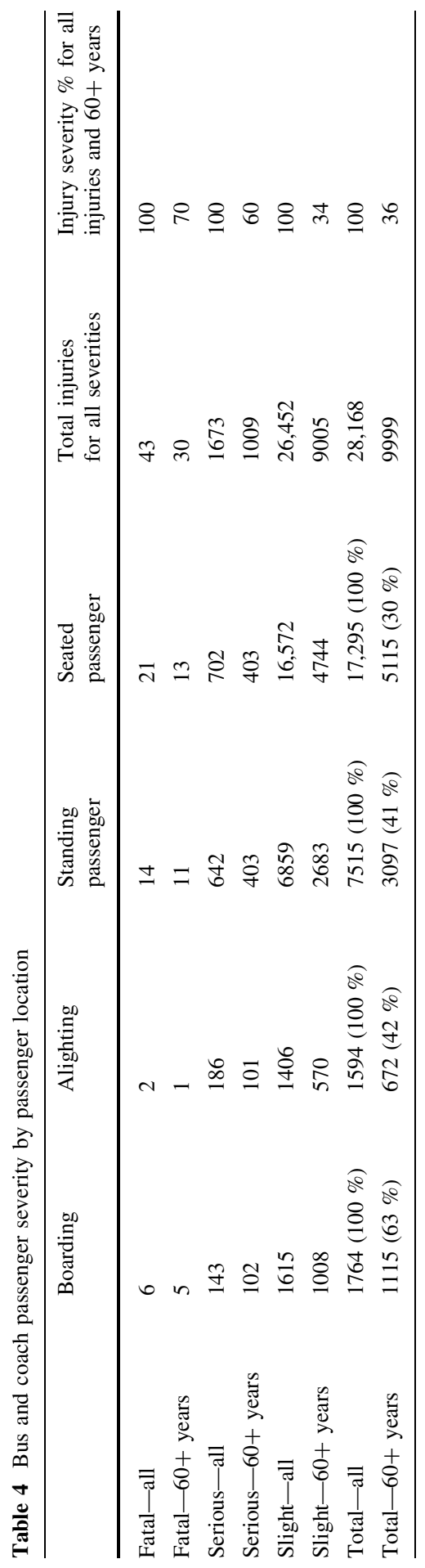


of casualties as in the 70-79 years group but the proportion of 'slight' injuries was higher in the younger group.

Passengers are categorised at the time of the incident into a particular location and Table 4 shows the distribution of the passenger locations. For all passengers the majority of all the injuries occurred whilst seated $(61 \%, \mathrm{n}=17,295)$ of these $30 \%$ $(\mathrm{n}=5115)$ were older passengers. For the other passenger locations older passenger sustained $63 \%(n=1115)$ of all boarding injuries, $42 \%(n=672)$ of all alighting injuries and $41 \%(\mathrm{n}=3097)$ of all standing injuries. Examining each passenger location and excluding 'slight' injuries older passengers sustained higher severity injuries when boarding the bus $(72 \% \mathrm{n}=107)$ or when standing $(63 \% \mathrm{n}=414)$, compared to seated $57.5 \%(\mathrm{n}=416)$ or alighting $(\mathrm{n}=102)$.

Overall $36 \%(n=9999)$ of all injuries $(n=28,168)$ occurred in the older passenger group; however, the severities of the injuries sustained were higher in this age group. Some $70 \%(n=30)$ of all the fatalities and $60 \%(n=1009)$ of all serious injuries were sustained by older passengers compared to only $34 \%$ $(\mathrm{n}=9005)$ of all the slight injuries sustained.

\subsection{HES/STATS19 linked data analysis}

Overall, a total of 4352 linked records were available for analysis for the period 1999 to 2009. Of these, some 1016 records of older (aged 60+) bus/coach passengers were available for analysis with $63 \%$ of the passengers aged over 75 years (Table 5). Of the 1016 passengers, 793 were female (78\%) and 223 male (22\%).

Table 6 shows the passenger location, bus manoeuvre and injury severity and also identifies that $62 \%(n=628)$ of all casualties occurred following a noncollision incident. The main cause of injury for standing and seated passengers was during normal bus driving manoeuvres mid-journey. As would be expected the boarding and alighting passengers were injured whilst the bus was stationary but $55 \%$ of all alighting and $40 \%$ of boarding passengers were recorded as being injured whilst the bus was manoeuvring. This suggests that there may be some discrepancy in the recording of the incidents of which $27 \%$ were classed as midjourney across these 2 passenger locations, normally a bus manoeuvre not

Table 5 Age distribution of bus and coach passengers aged over 60

\begin{tabular}{lcc}
\hline Age category & Frequency & $\%$ \\
\hline $60-64$ & 102 & 10.0 \\
$65-69$ & 102 & 10.0 \\
$70-74$ & 170 & 16.7 \\
$75-79$ & 177 & 17.4 \\
$80-84$ & 246 & 24.2 \\
$85-89$ & 152 & 15.0 \\
$90-94$ & 64 & 6.3 \\
$95-99$ & 3 & 0.3 \\
Total & 1016 & 100 \\
\hline
\end{tabular}




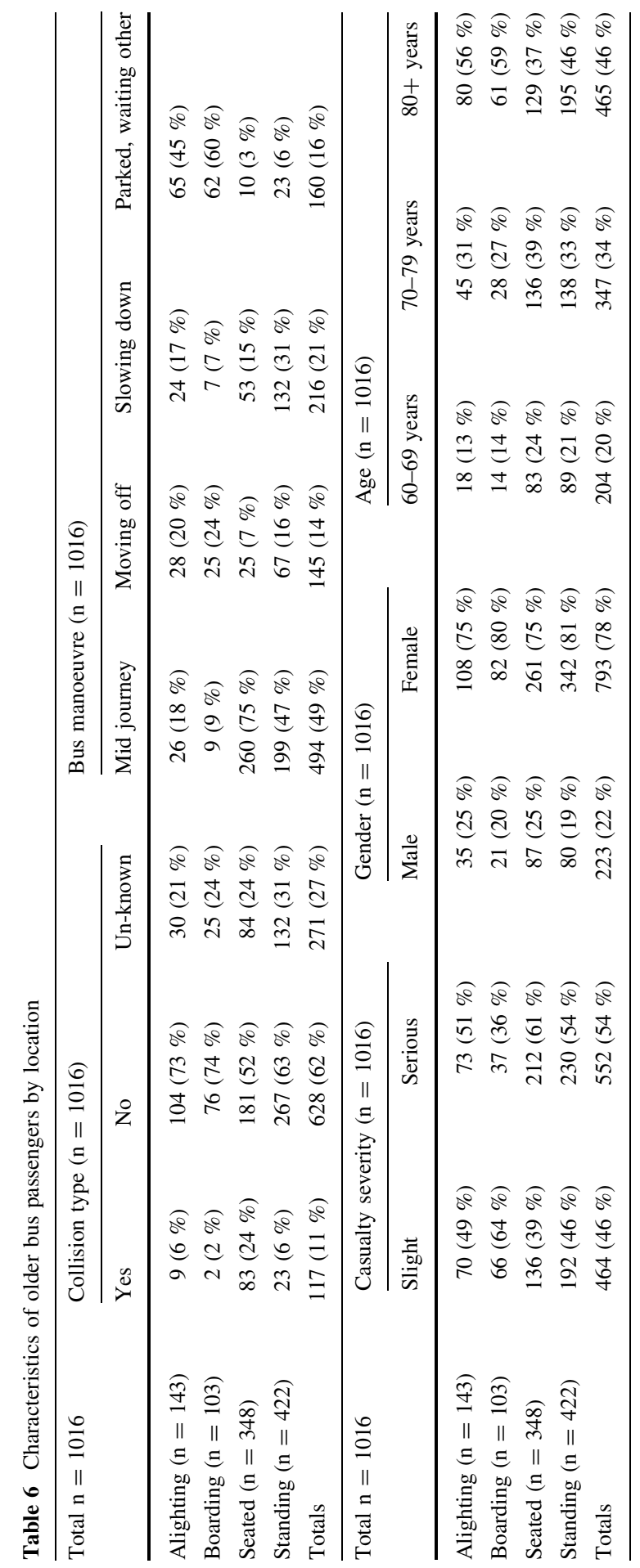


associated with alighting or boarding. Further to this, the distribution of injury severity identified more 'serious' injuries occurring whilst seated and predominantly 'slight' injuries occurring on boarding. Overall the risk of injury increased as age increased with $46 \%$ of older bus/coach passengers in the $80+$ years and only $20 \%$ in the 60-69 years.

In total, the injured bus passengers sustained 1381 injuries following the bus/coach incident. Overall injuries to the upper extremities, lower extremities and head predominated, with almost one-third of injuries involving the lower extremities. The distribution of the injuries by body region varied depending on known passenger location at the time of the incident (Table 7, $\mathrm{n}=1308$; this excludes multiple injuries and unspecified injuries). There was a significantly increased likelihood of sustaining more head and chest injuries whilst seated; chest and trunk injuries whilst standing and lower extremity injuries on boarding and alighting $\left(\chi^{2} 109.26\right.$ d.f. $\left.=12, \mathrm{p}<0.05\right)$. For upper extremities it appeared not to matter where the passenger was located.

The severity of the casualties could be further categorised according to the most serious injury sustained by the individual based on their Maximum AIS score (MAIS), Table 8 . In $18 \%$ of cases, an AIS code could not be attributed to at least 1 of the passengers' injuries and therefore the MAIS was unknown. Twenty-seven percent of the passengers had MAIS 1 and therefore 'minor' injuries were most severe. 'Moderate' or MAIS 2 injuries accounted for $28 \%$ of passengers and $26 \%$

Table 7 Distribution of body region injured and passenger location

\begin{tabular}{lrrrrrrrrr}
\hline & Alighting & $\%$ & Boarding & $\%$ & Seated & $\%$ & Standing & $\%$ & $\begin{array}{c}\text { Total body } \\
\text { region }\end{array}$ \\
\hline Head/neck & 37 & 19 & 17 & 14 & 181 & 38 & 153 & 29.5 & 388 \\
Chest & 5 & 3 & 7 & 6 & 53 & 11 & 48 & 9 & 113 \\
Trunk/lower back & 11 & 6 & 5 & 4 & 31 & 7 & 49 & 9 & 96 \\
Upper extremities & 38 & 20 & 20 & 16 & 94 & 20 & 114 & 22 & 266 \\
Lower extremities & 99 & 52 & 74 & 60 & 113 & 24 & 159 & 30.5 & 445 \\
Total & 190 & 100 & 123 & 100 & 472 & 100 & 523 & 100 & 1308 \\
\hline
\end{tabular}

Table 8 Distribution of MAIS categories for passengers $60+$ years

\begin{tabular}{lcc}
\hline & $60+$ years & $\%$ \\
\hline MAIS 1 & 275 & 27.1 \\
MAIS 2 & 284 & 28 \\
MAIS 3 & 261 & 25.7 \\
MAIS 4 & 11 & 1 \\
MAIS 5 & 1 & 0.1 \\
MAIS 6 & 4 & 0.4 \\
MAIS 9 (unknown MAIS) & 180 & 17.7 \\
Total & 1016 & 100 \\
\hline
\end{tabular}




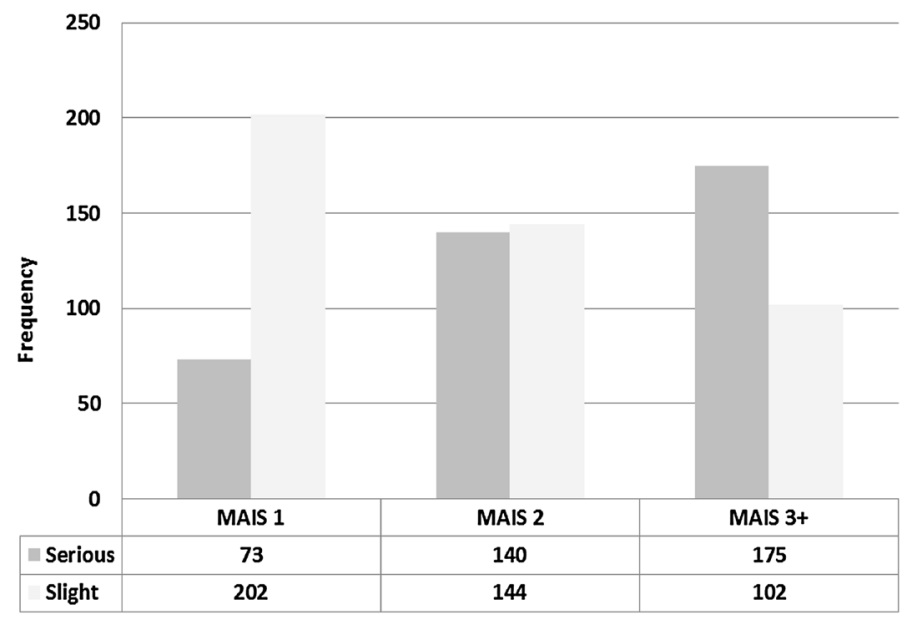

Fig. 1 Frequency of known MAIS and police casualty severity classification

Table 9 Distribution of MAIS by passenger location

\begin{tabular}{lcrlrrrrr}
\hline & Alighting & $\%$ & Boarding & $\%$ & Seated & $\%$ & Standing & $\%$ \\
\hline MAIS 1 & 32 & 26 & 47 & 53 & 98 & 36 & 98 & 28 \\
MAIS 2 & 42 & 33 & 27 & 30 & 90 & 33 & 125 & 36 \\
MAIS 3+ & 52 & 41 & 15 & 17 & 83 & 31 & 127 & 36 \\
Total & 126 & 100 & 89 & 100 & 271 & 100 & 350 & 100 \\
\hline
\end{tabular}

of passengers sustained 'serious' (MAIS 3) injuries. $1.5 \%$ of passengers sustained MAIS 4+ ('Severe' to Maximum) injuries.

Interestingly and as can be seen in Fig. 1, the distribution of passengers with a known MAIS injury severity and their corresponding police injury severity code reveals a variation between the two severity ratings. Whilst there is some consistency at the MAIS 2 level, there is a notable difference in the MAIS 3+ category where some $37 \%(\mathrm{n}=102)$ of passengers who were clearly 'Seriously' injured (due to sustaining MAIS 3+ injury) were categorised as 'Slight' in the police STATS 19 records. This suggests that under-reporting of injury severity may be a significant issue in the UK Police reporting system.

The distribution of known MAIS for passenger location suggests that there was a significant likelihood of sustaining MAIS 2 and MAIS 3+ injuries when standing (Table 9). Alighting passengers also were at risk of a significantly increased likelihood of sustaining serious (MAIS 3+) injuries. For those passengers boarding and being seated on the bus, their injury severity was more likely to be minor (MAIS 1) injuries $\left(\chi^{2} 28.23\right.$ d.f. $\left.=6, \mathrm{p}<0.0001\right)$. 
Alighting and boarding buses were both significantly more likely to cause injuries for the older passengers 80+ years. Passengers between 60 and 79 years were significantly more likely to sustain injuries whilst seated whereas the data suggests that all ages are at risk of injury whilst standing on buses; although the 60-69 years age group have a slightly increased likelihood of sustaining injuries standing $\left(\chi^{2} 41.07\right.$ d.f. $\left.=9, \mathrm{p}<0.0001\right)$.

\section{Discussion}

Although UK national injury rates are low for bus and coach passengers $(2.7 \%)$ the age-group $60+$ years are over-represented in the casualty figures $(8.4 \%)$. Furthermore, some $47 \%$ of the overall bus and coach casualty costs were attributed to those aged over 60 years. These higher figures possibly reflect the higher exposure to this transportation method compared to younger travellers. However, the injury risks associated with the physiological effects of ageing are also higher. This factor was evident in this study as the rate of 'serious' injury tended to increase with age. Interestingly and as was found in other studies, non-collision incidents predominate in injury causation for bus/coach passengers (Jovanis et al. (1991); Kirk et al. 2003).

Passenger location at the time of the incidents also had an impact on the injury outcome in terms of body region injured and also injury severity. The main body regions injured were the head and the lower and upper extremities and 'standing' was associated with sustaining more injuries, closely followed by being seated. Intuitively, this points towards loss of balance during various vehicle manoeuvres. When examining the severity of injuries using the MAIS level it was identified that 'Standing' and 'Alighting' were the main passenger actions for sustaining 'serious' MAIS 3+ injuries. 'Boarding' and 'Seated' passengers tended to sustain injuries that were more 'minor' (MAIS 1) in nature. Previous studies have also identified standing passengers to have higher incidences of injuries (Nue Moller et al. 1982; Halpern et al. 2005; Albrektsen and Thomsen 1983) whilst the study by Kirk et al. (2003) identified high incidence rates for 'seated' passengers.

Many incidences of injury have been associated with sudden braking or accelerating (Halpern et al. 2005) although this study tended to reveal higher incidences of injury that occurred in the mid-journey phase (46\%). However, particularly noticeable were the discrepancies in passenger location and bus manoeuvres - it would be expected that alighting and boarding incidents would be associated with a 'parked' or 'stationary' vehicle but this was only recorded for 45 and $60 \%$ of these incidents, respectively. $20 \%$ of alighting incidents were recorded during 'moving off' manoeuvres which are of concern since passengers should have exited from the vehicle prior to the bus departing. In addition, some $24 \%$ of boarding incidents were classed as 'moving off' and it is presumed that these represent incidences whereby the driver continued the journey before the passengers were correctly seated. This categorisation of passenger location is somewhat limited for examining injury causation as there is scope for error and subsequent misclassification as alighting incidents could be associated with moving through 
the bus or standing prior to getting off both of which can be interpreted as 'standing' whilst in the process of alighting the bus. For injury prevention strategies extra passenger location codes would be of future benefit in the design of countermeasures.

Analysis of the linked data allowed for injuries to be explored further and the varying severity levels to be collated and coded to an internationally recognised injury scale. What was highly evident in this study was the mismatch between police severity categories and hospital severity categorisation of the same injuries. Of most concern with regard to MAIS 3+ injury severity is that $37 \%$ of these injuries were categorised as 'Slight' in the STATS19 data. Similarly, $51 \%$ of 'Moderate' injuries, often consisting of fractures to the wrist, ribs or spine, were categorised as 'Slight' whereas the STATS20 guidelines clearly indicate that such injuries should be coded as 'Serious' casualties. These inaccuracies in the STATS19 data have been highlighted previously (Jeffrey et al. 2009) but it is evident that a large proportion of casualty severities in this study were miscoded in the STATS19 data suggesting that the morbidity and casualty costs are also under-estimated. This issue has been addressed and recommendations for helping police officers to more accurately categorise injury severity at the scene are being proposed (Ward et al. 2010).

Another limitation includes the small number of road accident records that were linked for bus and coach passengers which probably leads to under-representation (1\%). Furthermore, it was found that whilst $58 \%$ of linked casualties were correctly coded as 'Serious' with the remainder being coded slight, $42 \%$ of road accident injury statistics may be underestimated in terms of severity. Furthermore the data analysed for this paper were for bus and coach passengers as they are not distinguishable in the STATS19 dataset. This has potential implications when considering injury causation as there are differences in travelling speeds and possible passenger behaviour between the two vehicles. It is known that passengers have more freedom of movement within the bus but on coaches there is a tendency to stay seated with seatbelt in situ; therefore, this should be taken into consideration when interpreting the data.

One of the main aims of the study was to establish injury causation patterns of older bus passengers and overall the national data has provided an insight into these issues but there is potential for under-recording of injury severity and also cause associated with passenger locations. It is recommended that extra passenger location codes are included within the police CRASH system for collecting data. Furthermore, the recommendations from Ward et al (2010), if adopted, would improve the police reporting of 'slight' and 'serious' casualties. These analyses used national datasets and are limited to those incidents reported to the police and for those linked cases who attended hospital. Further analysis will be undertaken of Bus Company data where it is expected that higher numbers of incidents occur that are not required to be reported to the police and therefore do not appear in any national data but are potentially rich sources of data for exploring injury causation in detail.

The results from this study suggest that sufficient information can be gained in order to consider countermeasures to injury during bus-use although more detailed information from in-depth studies would be of benefit. One of the main 
considerations for injury prevention includes an appraisal of existing operational procedures to ensure that in all cases, passengers have properly exited from vehicles or are correctly seated at the time the bus moves away from the stop which could assuage some of the boarding and alighting incidents identified in this study. Such operational aspects will be reported in a follow-up study but it is clear that attention to such aspects could lead to a prevention of many of the injuries that occurred in this study and improvements to them could be easily achieved without radical (if any) changes to the design of the bus interior. However, more immediately some interior design considerations are evident which have been explored within the study (which will be reported at an in-depth level in a follow-up paper). Examples of such design factors include positioning of grab-handles (for passengers traversing up and down the bus whilst in transit- there should be more of them and they should be located more accessibly), seat characteristics (passengers were found to slide off side-facing seats in some cases), stop-button locations (some passengers had to stand to reach them) and floor designs (some of which can become very slippery under wet conditions). However, it is acknowledged that re-design of bus interiors has to be based on a strong evidence-base and this could be more easily achieved with accurate information about injury causation. This could be achieved through more systematic investigations of relevant incidences-at the moment, scope exists for improving the data collection process for incidences on buses, especially where serious injury has occurred and this study suggests that an injury surveillance system relating to the more serious events occurring on public buses would be of great benefit to the community.

Acknowledgments This research is funded by the MRC Lifelong Health and Wellbeing programme (LLHW), Grant Number G1001863/1. LLHW is a cross council initiative in partnership with the UK health departments and led by the MRC. The linked dataset "Copyright(C 2009, Re-used with the permission of The Health and Social Care Information Centre and Department for Transport. All rights reserved".

Open Access This article is distributed under the terms of the Creative Commons Attribution 4.0 International License (http://creativecommons.org/licenses/by/4.0/), which permits unrestricted use, distribution, and reproduction in any medium, provided you give appropriate credit to the original author(s) and the source, provide a link to the Creative Commons license, and indicate if changes were made.

\section{References}

AAAM (1990) The Abbreviated Injury Scale. Revision, Update 98. Association for the Advancement of Automatic Medicine, Barrington

Albrektsen SB, Thomsen JL (1983) A casualty ward analysis of bus passenger accidents. Med Sci Law 23(2):102-105

Barnes J, Morris AP (2014) Injuries to older users of public transport-a neglected problem. Traffic Inj Prev 15:S245-S247

Department for Transport (2005) Instructions for the completion of road accident reports-STATS20. Department for Transport, London

Department for Transport (2012) Linking Police and Hospital data on Road Accidents in England: 1999 to 2009. Department for Transport, London 
Department for Transport (2012) Reported accidents vehicles and casualties (2012) (RAS40). https://www. gov.uk/government/statistical-data-sets/ras40-reported-accidents-vehicles-and-casualties. Accessed 10 June 2015

Department for Transport (2013) Reported Road Casualties Great Britain (2012) Annual Report. Department for Transport, London

ECIP (2006) European center for injury prevention. Algorithm to transform ICD-10 codes into AIS 90 (98 update)version 1.0 for STATA. University of Navarra, Pamplona, Spain

Fildes B, Morris AP, Barnes J (2012) Analysis of injuries to young and old victorian public transport users; 2006-2010; report 319, Monash University, Melbourne

Halpern P, Siebzehner MI, Aladgem D, Sorkine P, Bechar R (2005) Non-collision injuries in public buses: a national survey of a neglected problem. Emerg Med J 22(2):108-110

http://www.ons.gov.uk/ons/rel/npp/national-population-projections/2012-based-reference-volume-seriespp2/results.html\#tab-Age-Structure. Accessed 10 June 2015

Jeffrey S, Stone DH, Blamey A, Clark D, Cooper C, Dickson K, Mackenzie M, Major K (2009) An evaluation of police reporting of road casualties. Inj Prev 15(1):13-18

Jovanis PP, Schofer JL, Prevedouros P, Tsunokawa K (1991) Analysis of bus transit accidents: empirical, methodological and policy issues. Transp Res Rec 1322:17-28

Kendrick D, Drummond A, Logan P, Barnes J, Worthington E (2015) Systematic review of the epidemiology of non-collision injuries occurring to older people during use of public buses in highincome countries. J Transp Health 2(3):394-405

Kirk A, Grant R, Bird R (2003) Passenger casualties in non-collision incidents on buses and coaches in Great Britain. In: Proceedings of 18th international technical conference on the enhanced safety of vehicles. Nagoya, Japan 19-22 May 2003

Lucas K, Tyler S, Christodoulou G (2008) The value of new public transport in deprived areas: Who benefits, how and why?. Joseph Rowntree Foundation, New York

Mabrook AF (1994) Injuries sustained by passengers on buses. J Accid Emerg Med 11(3):209-210

Nue Moller B, Grymer F, Christensen ST, Moller-Madsen B, Hermansen C (1982) Bus Accidents. J Traffic Med 10(4):59-62

Ward H, Lyons R, Gabbe B, Thoreau R, Pinder L, Macey S (2010) Review of police road casualty injury severity classification-a feasibility study, Department for Transport

WORLD HEALTH ORGANIZATION (1992) The ICD-10 classification of mental and behavioural disorders: clinical descriptions and diagnostic guidelines. World Health Organization, Geneva 